\title{
Ego Strength and Anxiety among Working and Non-working Women
}

\author{
Balvant M. Chhansiya ${ }^{1}$, Yogesh A. Jogsan ${ }^{2}$
}

\section{ABSTRACT}

The main purpose of this research was to find out the mean difference between working and non working women. The total 80 women as a variation belonging to working and non working women were taken. The research tool for Ego Strength was measured by Hasan's Ego strength Scale and tool for anxiety were used which made by Sinha. Here t-test was applied to check the significant of in Ego strength and Anxiety between working and non working women. To check the relation between Ego strength and anxiety correlation method is used.

The study revealed that there was significant difference between working and non working women in Ego strength. There was significant difference between working and non working women in anxiety. While the correlation between Ego strength and anxiety reveals 0.54 positive correlation.

Keywords: Ego Strength and Anxiety

An understanding of the concept of ego strength depends on an understanding of the ego functions because, "We are used to judging the strength of the ego on the basis of its behavior in typical situations (Hartmann, 1964)." If we know what the ego is expected to do, we are in a position to determine how well it is copping it, that is, how strongly it is functioning. Ego strength is a measure of the effectiveness with which the ego is performing its task of adapting to the demands of reality (Hartmann, 1958). In other words, it is the ego's task to assess the requirements of reality and to see that the individual's needs are met within that framework. Thus, it is understandable that much of the psychological research dealing with unwed mothers focuses on the idea of a deficiency in ego strength. This research will be discussed in the following section.

${ }^{1}$ Department of Psychology, Suarashtra University, Rajkot

${ }^{2}$ Prof., Department of Psychology, Suarashtra University, Rajkot

(C) 2015 I B Chhansiya, Y Jogsan; licensee IJIP. This is an Open Access Research distributed under the terms of the Creative Commons Attribution License (http://creativecommons.org/licenses/by/2.0), which permits unrestricted use, distribution, and reproduction in any Medium, provided the original work is properly cited. 
Ego Strength refers to virtues through which "human beings steer themselves and others though life" (Erikson, 1964). In his psychosocial stage theory (Erikson 1964) identified strengths as outcomes of successful stage resolutions. Faith Development includes two aspects, i.e. the frequency of participation in faith related activities and the level of importance respondents attributed to faith.

The ego strengths are under examined components of Erikson's broader psychosocial theory of human development. The absence of scholarly discussion on this topic is significant because, theoretically, the ego strengths should provide evidence of successful psychosocial stage resolutions. The ego strength of hope emerges from the successful resolution of trust vs. mistrust in infancy. Will emerges from autonomy versus shame/doubt while purpose results from successful resolution of initiative versus guilt in early childhood. Competence emerges from industry versus inferiority during latency; fidelity emerges from identity versus identity confusion in adolescence; love emerges from intimacy versus isolation in young adulthood; care emerges from generativist versus stagnation in middle adulthood; and wisdom emerges from integrity versus despair in later adulthood. Like the psychosocial stages, the ego strengths are thought to be sequential, invariant, and hierarchical.

Anxiety occupies a focal position in the dynamics of human behavior it is a common reaction to frustration. Since anxiety is highly distressing, indeed one of the most intolerable psychic states with which the human organism has to deal, it demands some sort of adjustment which will afford relief. A large part of human adjustment is concerned with avoiding or relieving anxiety. Growing out of many frustrating situations, anxiety serves as the driving force for a large number of subsequent adjustments.

In behavioral terms Sarason (1980) defined anxiety as a conditioned response to a perceived threatening stimulus which could be learned or inherited. Benjamin (1987) noted that anxiety can interface with attention, learning and testing. The idea that anxiety may interface with a student's ability to demonstrate what they have learned is not new. Anxiety can also interface with learning in that anxious students are more easily distracted by irrelevant or incidental aspects of the task at hand, having trouble in focusing on significant details.

Anxiety may be defined as mental distress with respect to some anticipated frustration. It this sense, it is to be distinguished from the immediate response to frustration itself, which is reacted to with aggression, or the danger whish is reacted to with fear. Whatever the frustration is, it is recognized as dangerous because it will result in either pain or loss. The essence of human learning is that the individual shall acquire the capacity for recognizing by certain signs or cause, situations which promise to satisfy his need or cause him harm so that he can anticipate them on some future occasion and thereby make ready to accept and use those that satisfy and avoid those which promise to frustrate. 


\section{Ego Strength and Anxiety among Working and Non-working Women}

Anxiety is also a function of the extent to which the person himself is involved in the danger. If the anticipated danger is the bite of an insect, a scratch on the skin by a cat, or the loss of one's hat on a windy day, the anxiety, while real, will not be so intense as when the existence or safety of the person is threatened. Here, too, the threat that causes the most severe, anxiety may not necessarily be one that involves physical danger. The most acute anxiety arises when the individual feels that his personal adequacy or his existence in the group is threatened.

Types of anxiety disorders:

1. Generalized anxiety disorders

2. Panic disorders

3. Phobias

4. Obsessive-compulsive disorders

5. Post-traumatic stress disorders

6. Understanding anxiety disorders.

Mohammad Nadeem et al.(2012).Impact of Anxiety on the Academic Achievement of Students Having Different Mental Abilities at University level in Bahawalpur (Southern Punjab) Pakistan. The results show that when anxiety increases, academic achievement decreases both in male and female students. It is also noteworthy in the results that there is more impact of anxiety on female students as compared to male students.

R.M.Shepherd and R.J.Edelman. The inter relationship of social anxiety with anxiety, depression, locus of control, ways of coping and ego strength amongst university students. There were high scores of social anxiety which were related to high scores on measures of anxiety and depression, low ego strength, external locus of control and emotion coping rather than problem focused coping.

J.W.Worden and H.J.Sobel(2012). Ego strength and psychosocial adaptation to cancer patient. Results showed that psychosocial adaptation to cancer was related to a patient's ego strength. As correlated positively with a patient's use of effective coping strategies.

Pooja Chatterjee and Kerryann Walsh(2010). Anxiety among high school students in India: Comparisons across gender, school type, social strata and perceptions of quality time with parents. Results show that anxiety was prevalent in the sample with $20.1 \%$ of boys and $17.9 \%$ of girls found to be suffering from high anxiety. More boys were anxious than girls. Adolescents from Bengali medium schools were more anxious than adolescents from English medium schools. 


\section{RESEARCH PROBLEM:}

"Ego Strength and Anxiety among Working and Non-working Women"

\section{OBJECTIVES:}

The main objectives of study were as under.

1. To measure the ego strength among working and non-working women.

2. To measure the anxiety among working and non-working women.

3. To measure the correlation between ego strength and anxiety.

\section{HYPOTHESIS:}

To related objectives of this null hypothesis were as under.

1. There is no significant difference in ego strength among working and non-working women.

2. There is no significant difference in anxiety among working and non-working women.

3. There is no correlation between ego strength and anxiety.

\section{METHOD}

\section{Participants:}

According to the purpose of present study total 80 sample has been selected. There were 38 working women and 42 non-working women were taken as a sample from different area in Rajkot city. (Gujarat)

\section{Research design:}

The aim of present study was to a study of ego strength and anxiety among working nonworking women. For these total 80 working and non-working women were taken as a sample. Here to the measure ego strength in the ego strength scale was used. This was made by Hasan. Check anxiety in them A.P.K Sinha anxiety scale was used. To check difference between group t-test and correlation method was used. The result discussion of ego strength and anxiety is as under.

\section{Tools:}

For this purpose the following test tools were considered with their reliability, validity and objectivity mentioned in their respective menus in present study two inventories is used.

a) Hasan's ego strength scale:

The inventory was developed by Hasan. In this scale contents 32 statements. Answer given in right or wrong symbol in a inventory. There reliability and validity are higher.

b) Sinha's anxiety scale: 
The Sinha's anxiety scale was use in present study. There are 100 statements in the scale and every statement has two alternatives responses yes or no. There reliability and validity are higher.

\section{Procedure:}

According to purpose of present study for data collection the investigator explained the purpose the study to the subjects for these total 38 working and 42 non-working women were taken as a sample from different part of Rajkot city (Gujarat). Testing was done personally with working and non-working women. The whole procedure of fill the inventory was explained to them fully and clearly. The instructions given on questionnaire were explained to them. It was also made clear to them that these scores would be kept secret. It was checked that non of the participants left any questions unanswered or that no participants encircled both the answer given against questions.

\section{RESULTS AND DISCUSSIONS}

The main objective of present study was to measure the "ego strength and anxiety of working and on-working women." In it statistical t-test method is used. To check correlation between ego strength and anxiety Karl Persian ' $r$ ' method is used. Result discussion of present study is as under.

Table-1

The table- 1 indicates that the mean score of ego strength in working women are 11.83 and nonworking women are 8.35. The standard deviations for both working women and non-working women's are 4.27 and 3.01 respectively. The difference between these two means is significant at 0.01 level of confidence as the value of t-test is 3.94 Findings shown that working women are more affected by ego strength in comparison to non-working women. Working women find themselves under more ego strength because of their multiple roles. The working outside home is seen as an added on role for working women while it is seen as substitute role in non-working women. So the first hypothesis is unaccepted.

Evidences of research finding given by R.M.Shepherd and R.J.Edelman(2009). Conducted study in the There were high scores of social anxiety which were related to high scores on measures of anxiety and depression, low ego strength, external locus of control and emotion coping rather than problem focused coping. Result was same as present study. There for we can say that present finding are supported by R.M.Shepherd and R.J.Edelman(2009). Also supported by J.W.Worden and H.J.Sobel's (2012) reseach.

Table-2

The table-2 indicates that the mean scores of anxiety in working women and non-working women are 22.18 and 18.18 the standard deviations for both working women and non-working women are 6.98 and 5.64 respectively. The difference between these two means is significant at 
0.01 level of confidence as the value of t-test is 4.28 a perusal of that reveals significant difference between anxieties of the two groups. In this study working women scored higher on anxiety in comparison to their non-working women counterparts. It is not surprising because in our culture, society renders more care, protection and support to non-working women. So the second hypothesis is also unaccepted.

Evidences of research finding given by Pooja Chatterjee and Kerryann Walsh(2010). Results show that more boys were anxious than girls. Adolescents from Bengali medium schools were more anxious than adolescents from English medium schools. Result was same as present study. There for we say that present finding are supported by Chatterjee and Kerryann Walsh's (2010) research.

Table-3

According to table-3 the results obtained positive co-relation between ego strength and anxiety. It was 0.54 positive co-relations between ego strength and anxiety. It means ego strength decrease anxiety decrease and ego strength increase anxiety increase.

Conclusion

We can conclude by data analysis as follows;

There were significant differences between the mean scores of two groups on ego strength. Working women are more affected by ego strength in comparison to non-working women and there were significant difference between the mean scores of two groups on anxiety. Working women scored higher on anxiety in comparison to their on-working women counterparts. It is not surprising because in our culture, society renders more care, protection and support to nonworkingwomen. The co-relation between ego strength and anxiety is 0.54 which is positive correlations.

\section{REFERENCES:}

American Psychiatry Association(1994).Diagnostic and statistical manual of mental disorders (DSM -4).Washinton DC.

Benjamin and Lin(1997) Psychology and Introduction. New York: McGraw Hill Book Company.

Erikson, E.H.(1964).Insight and responsibility. New York: Norton.

Hartmann, H.(1958).Ego psychology and the problem of adaptation. New York: International Universities Press, Inc.

Hartmann, H.(1964).Essays on ego psychology. New York: International Universities Press, Inc, p.p.134

J W Worden and H J Sobel(2012). Ego strength and psychosocial adaptation to cancer. Unpublished research paper. 
Mohammad Nadeem et al.(2012). Impact of Anxiety on the Academic Achievement of Students Having Different Mental Abilities at University level in Bahawalpur (Southern Punjab) Pakistan. International Online Journal of Educational Sciences, 2012, 4 (3), 519-528

Pooja Chatterjee \& Kerryann Walsh(2010). Anxiety among high school students in India: Comparisons across gender, school type, social strata and perceptions of quality time with parents. Australian Journal of Educational \& Developmental Psychology. Vol 10, pp18-31

R.M.Shepherd \& R.J.Edelman. The inter relationship of social anxiety with anxiety, depression, locus of control, ways of coping and ego strength amongst university students. College Quarterly Spring 2009 Vol. 12 No. 2

Sarason,I.G.(1958). Inter relationships among individual difference variables, behaviour in psychotherapy, and verbal conditioning. Journal of Abnormal and Social Psychology, 56, 339-334.

RESULT TABLES:

Table-1 Ego strength among working and Non-working women

\begin{tabular}{|l|l|l|l|l|l|l|}
\hline Sr. No. & Variable & N & Mean & SD & t & Sig. \\
\cline { 1 - 5 } \cline { 1 - 1 } 2. & Working Women & 38 & 11.83 & 4.27 & 3.94 & 0.01 \\
\cline { 1 - 4 } & $\begin{array}{l}\text { Non-working } \\
\text { Women }\end{array}$ & 42 & 8.35 & 3.01 & \\
\hline
\end{tabular}

Significance Level $\quad 0.05=2.02$

$0.01=2.71$

Table-2 Anxiety among working and Non-working women

\begin{tabular}{|l|l|l|l|l|l|l|}
\hline Sr. No. & Variable & N & Mean & SD & t & Sig. \\
\hline 1 & Working Women & 38 & 22.18 & 6.98 & 4.28 & 0.01 \\
\cline { 1 - 5 } 2. & $\begin{array}{l}\text { Non-working } \\
\text { Women }\end{array}$ & 42 & 18.18 & 5.64 & \\
\hline
\end{tabular}

Significance Level $\quad 0.05=2.02$

$0.01=2.71$

Table-3 Correlation of the ego strength and anxiety among working and Non-working women

\begin{tabular}{|l|l|l|l|l|}
\hline Sr. No. & Variable & N & Mean & r \\
\hline 1 & Ego Strength & 80 & 10.09 & 0.54 \\
\hline 2. & Anxiety & 80 & 20.18 & \\
\hline
\end{tabular}


Ego Strength and Anxiety among Working and Non-working Women

Chart - 1 Showings mean score of working and non-working women on anxiety

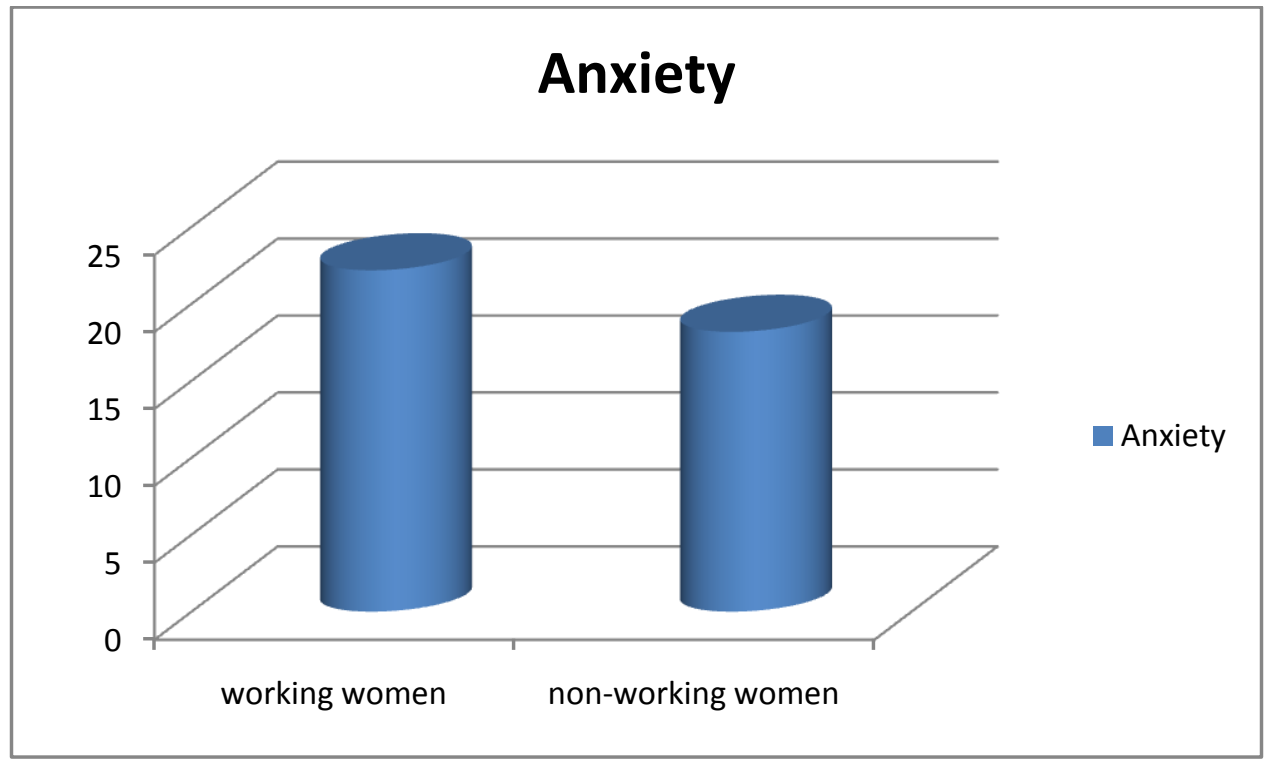

Chart - 2 Showings mean score of working and non-working women on ego strength

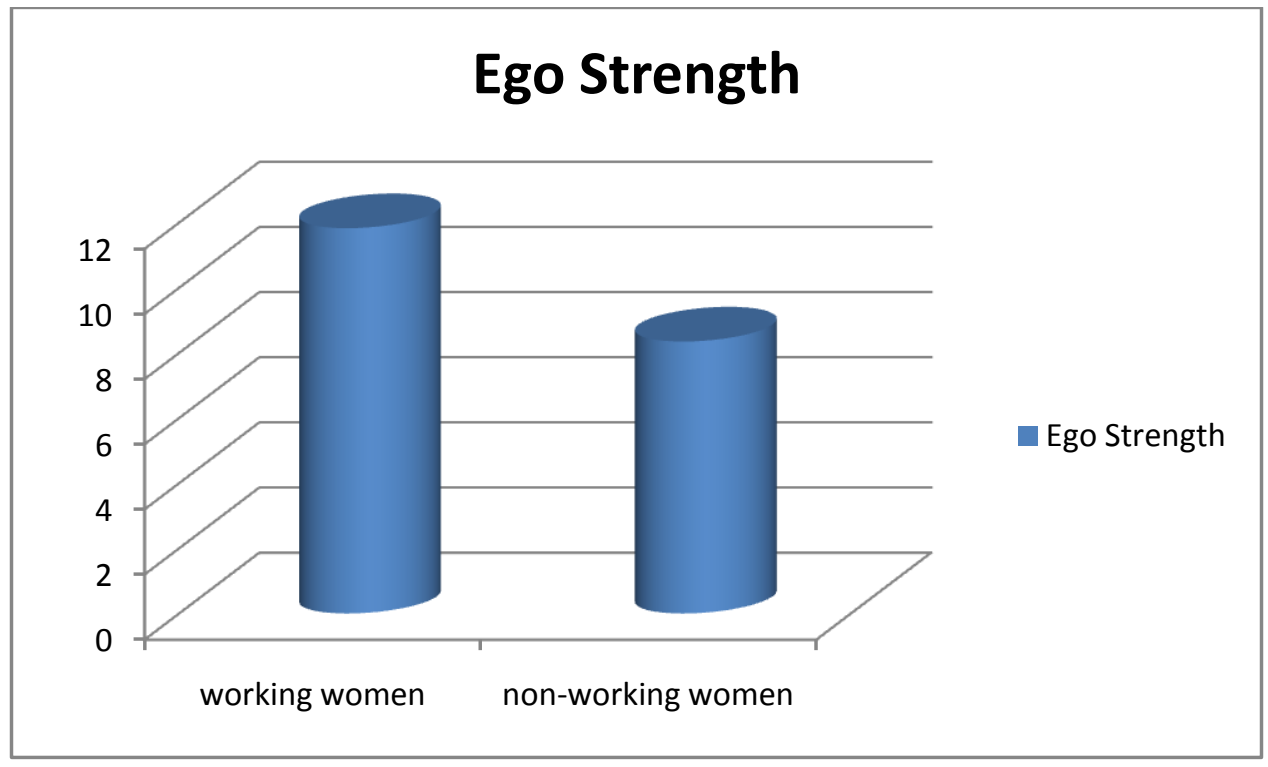

